\title{
Molecular authentication of the traditional Chinese medicinal plant Angelica sinensis based on internal transcribed spacer of nrDNA
}

\author{
Tu Feng \\ Laboratory of Systematic and Evolutionary Botany \\ College of Life Sciences \\ Sichuan University \\ Chengdu, China \\ Shuang Liu \\ Laboratory of Systematic and Evolutionary Botany \\ College of Life Sciences \\ Sichuan University \\ Chengdu, China \\ Xing-jin $\mathrm{He}^{*}$ \\ Laboratory of Systematic and Evolutionary Botany \\ College of Life Sciences \\ Sichuan University \\ Chengdu, China \\ E-mail: xjhe@scu.edu.cn
}

Financial support: Nationally Natural Science Foundation of China (No. 30670146) and the National Infrastructure of Natural Resources for Science and Technology (No. 2005DKA21403).

Keywords: Angelica sinensis, internal transcribed spacer, molecular authentication, specific primers, traditional Chinese medicine.

Present address: "Department of Environment and Life sciences, Bijie University, Bijie, Guizhou, China, 551700.

Abbreviations: AP-PCR: arbitraily primed PCR

ARMS: amplification-refractory mutation system

DMSO: dimethyl sulfoxide

GC: guanine-cytosine

ITS: internal transcribed spacer

MP: maximum parsimony

nrDNA: nuclear ribosomal DNA

RAPD: random amplified polymorphic DNA

RFLP: restriction fragment length polymorphism

SCAR: sequence characterized amplified region

TCM: traditional Chinese medicine

Traditionally, the authentication of the traditional Chinese medicines (TCM), Angelica sinensis, is based on slightly different morphological characters and complex compounds. Usually, those methods are simultaneously affected by several factors, leading to subtle and ambiguous results. In this study, the internal transcribed spacer (ITS) regions of $A$. sinensis and seven other Angelica species used as adulterants were sequenced. A pair of specific primers was designed from the polymorphic ITS regions to distinguish $A$. sinensis from the adulterants and regional substitutes. These ITS-derived primers amplified approximately 520 bp specific fragments from the adulterants, whereas no products was amplified with the DNA of $A$. sinensis. We tested eight commercially crude materials purchased in the market by using these specific primers. The result showed that there were four samples adulterating $A$. sinensis with regional substitutes. This indicated that $A$. sinensis could be accurately distinguished from the adulterants and regional substitutes. Therefore, the method of molecular authentication based on the ITS sequences may be contributed to raw material production and quality control of $A$. sinensis.

Angelica sinensis, known as "Dang gui" in China, is one of the most commonly used traditional Chinese medicines (TCM), and has been mainly used in the treatment of gynecological diseases. A. sinensis has been known for a long time for its effects of cleansing blood and increasing circulation, and utilized as a valuable remedy for anemia, menstrual irregularities in traditional Chinese medicine (Yang et al. 2002). Recent chemical and pharmacological studies of various compounds isolated from the herb were found to increase myocardial blood flow and reduce

*Corresponding author 


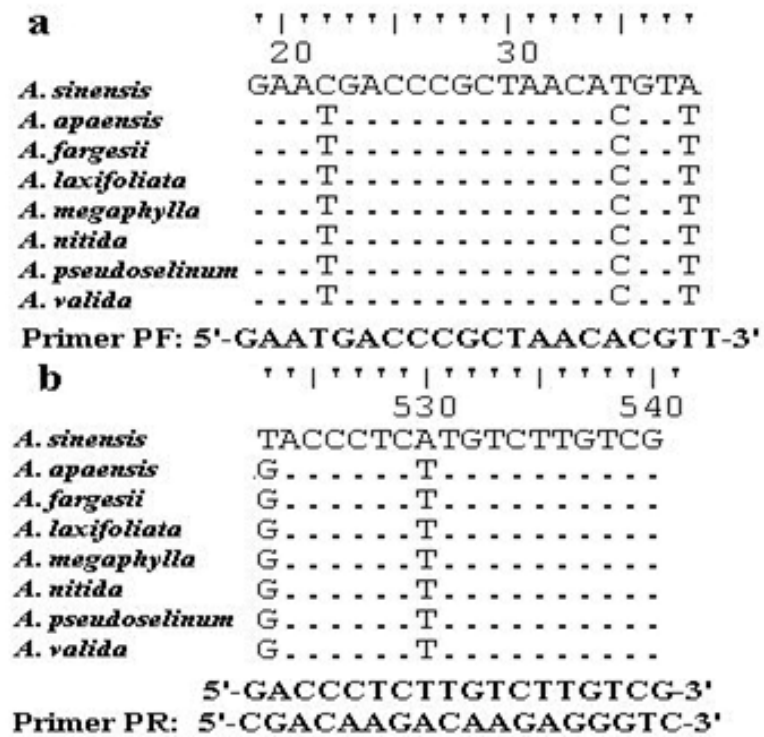

Figure 1. The specific primers in the divergent ITS regions of Angelica species. (a) The forward primer PF in ITS1 region; (b) The reverse primers PR in ITS2 region.

radiation damages. It was also reported that $A$. sinensis effected on the proliferation of human bone cells, and prevented ethanolor indomethacin-induced gastric mucosal damage (Ye et al. 2001; Ye et al. 2003).

A. sinensis, which belongs to Angelica genus, is edible and officinal. The genus Angelica (Apioideae, Peucedaneae, Angelicinae) is one of the relative large genera of the Apiaceae, and consists of 45 species (32 endemic) in China (Downie et al. 2000; She et al. 2005). Due to the slightly different morphological characters of Angelica species and their dried roots, several species are usually considered to be "Dang gui" by error. Some species (e.g. A. nitida, A. valida and $A$. megaphylla) are regional substitutes and adulterants for $A$. sinensis in China (She et al. 2005). However, the Pharmacopoeia of the People's Republic of China only states the Angelica sinensis (Oliv.) Diels to be the uniquely original and officinal herb (Editorial Board of Pharmacopoeia of the People's Republic of China, 2005). The regional substitutes and adulterants have little medicinal properties commonly. Inevitably, the confusion may compromise the genuine resources and therapeutic effect of this TCM; even imperil the safety of consumers.

The traditional methods are mainly based on the slight difference of morphological characters and analysis of compounds by high performance liquid chromatography (HPLC) fingerprints to distinguish $A$. sinensis from adulterants (Lu et al. 2005; Wang et al. 2007). The accuracy of authentication has limitations because of the amounts of samples, the stability of chemical constituents, the variable sources and the chemical complexity. However, DNA can be extracted from fresh or dried organic tissue of the plant materials and is not restricted by the form of the samples. DNA markers are reliable for informative polymorphisms as the genetic composition is unique for each species. Hence, DNA markers, such as PCR-restriction fragment length polymorphism (PCRRFLP), amplification-refractory mutation system (ARMS), arbitrarily primed PCR (AP-PCR), random amplified polymorphic DNA (RAPD), sequence characterized amplified region (SCAR) and DNA sequencing, are useful for the authentication and standardization of medicinal plant species (Joshi et al. 2004).

The internal transcribed spacer (ITS) of nuclear ribosomal DNA (nrDNA) is a particularly valuable marker for phylogenetic analysis at interspecific-level and intergeneric-level among angiosperms and other eukaryotes (Baldwin et al. 1995). Because the popularity of ITS in phylogeny derived from several merits, such as biparental inheritance, universality, simplicity, intragenomic uniformity, intergenomic variability, low functional constraint and high copy number, the ITS is one of the most extensively applied molecular markers for angiosperm phylogenetic inference and genetic relatedness (Álvarez and Wendel, 2003; Biffin et al. 2007). It also has been successfully used as a genetic marker for molecular authentication and identification of several medicinal plants and fungi, such as Panax ginseng (Ngan et al. 1999; Kim et al. 2007), Dendrobium Species (Lau et al. 2001; Ding et al. 2003; Xu et al. 2006), Euphorbia pekinensis (Xue et al. 2006), Bupleurum species (Yang et al. 2007), Boletus edulis (Lian et al. 2008). Furthermore, the specific primers which based on the divergent ITS regions were designed

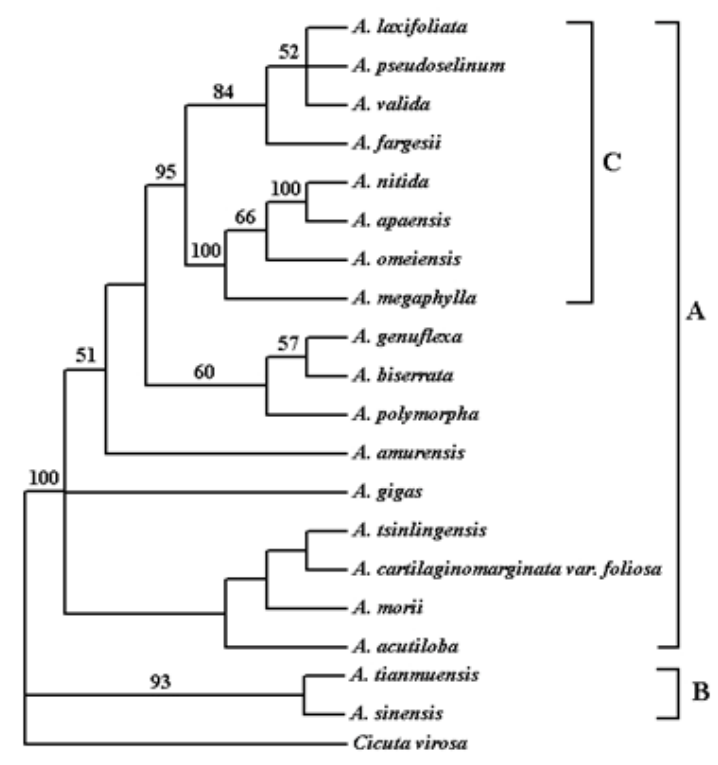

Figure 2. The $50 \%$ majority-rule consensus tree of MP analysis derived from ITS sequences. Bootstrap values appeared above the branches and the values $<50 \%$ were not indicated. The clade A includes most of Angelica species, and the clade $B$ encompasses $A$. tianmuensis and the genuine herb, $A$. sinensis. The group $C$ includes several familiar adulterants and regional substitutes. 
Molecular authentication of Angelica sinensis based on ITS of nrDNA

Table 1. The sources and accession numbers of ITS sequences from original materials.

\begin{tabular}{|c|c|c|c|}
\hline Species & Voucher & Geographical origin & Accession number \\
\hline A. apaensis & SZ20060614 & N: $31^{\circ} 54.211^{\prime} ; \mathrm{E}: 102^{\circ} 39.723^{\prime}$ & EU418381 \\
\hline A. fargesii & SZ20060715 & N: $31^{\circ} 48.514^{\prime} ; \mathrm{E}: 108^{\circ} 46.539^{\prime}$ & EU418376 \\
\hline A. laxifoliata & SZ2006071804 & N: $30^{\circ} 03.543^{\prime} ; \mathrm{E}: 101^{\circ} 48.881^{\prime}$ & EU647210 \\
\hline A. megaphylla & SZ20060706 & N: $29^{\circ} 05.200^{\prime} ; \mathrm{E}: 107^{\circ} 15.114^{\prime}$ & EU418377 \\
\hline A. nitida & SZ2006080501 & N: $32^{\circ} 44.529^{\prime} ; \mathrm{E}: 103^{\circ} 42.045^{\prime}$ & EU418378 \\
\hline A. pseudoselinum & SZ2006071601 & N: $30^{\circ} 45.008^{\prime} ; \mathrm{E}: 102^{\circ} 78.602^{\prime}$ & EU418379 \\
\hline A. sinensis & SZ20080816 & N: $30^{\circ} 41.452^{\prime} ; \mathrm{E}: 104^{\circ} 09.315^{\prime}$ & FJ204235 \\
\hline A. valida & SZ2006070701 & N: $29^{\circ} 06.985^{\prime} ; \mathrm{E}: 107^{\circ} 14.028^{\prime}$ & EU418380 \\
\hline
\end{tabular}

and used for the authentication of the original plants and adulterants. Based on the nucleotide substitutions within the ITS regions among four Atlactylodes species, a PCR-based method was established for the rapid identification and discrimination of So-jutsu (Atractylodes lancea rhizome) and Byaku-jutsu (Atractylodes rhizome) without sequencing (Guo et al. 2006). Ding et al. (2003) authenticated the stems of Dendrobium officinale in China by the ITS specific primers for diagnostic PCR. Xu et al. (2006) designed five pairs of species-specific primers and used them for the rapid PCR identification of five Dendrobium species which listed in the Pharmacopoeia of the People's Republic of China. Lin et al. (2006) accurately identified of the bulbs of Pinellia ternata based on the specific primers in ITS regions. These results indicated that the authentication of medicinal plants by using ITS regions and their divergent sequences was effective and accurate (Ding et al. 2003; Lin et al. 2006).

In this paper, we designed the specific primers based on the divergent ITS regions and successfully authenticated the adulterants from $A$. sinensis. In comparison to the traditional methods of authenticating Angelica species, the method reported in this paper was reliable and highly sensitive, and was not affected by the chemical conditions and the sample amount. This is the first report on authenticating the adulterants from A. sinensis by ITS sequence analysis.

\section{MATERIALS AND METHODS}

\section{Materials and genomic DNA extraction}

The fresh leaf materials were sampled in fields and identified by Prof. Xingjin He. The herbaria were deposited in the Museum of Nature and History, Sichuan University. The sources of ITS sequences from original materials in this study are listed in Table 1.

Total genomic DNA was extracted from silica-gel-dried leaf and commercially crude materials using a modified CTAB procedure (Cota-sánchez et al. 2006).

\section{PCR amplification and sequence analysis}

The ITS region (including ITS1, 5.8SrDNA and ITS2) was amplified using the universal primers ITS4 (5'TCCTCCGCTTATTGATATGC-3') and ITS5 (5'GGAAGTAAAAGTCGTAACAAGG-3') (White et al. 1990). PCR amplification was carried out under the following conditions: initial denaturation at $94^{\circ} \mathrm{C}(1 \mathrm{~min})$; followed by 30 cycles of $94^{\circ} \mathrm{C}$ denaturation $(1 \mathrm{~min}), 55^{\circ} \mathrm{C}$ annealing (70 sec), and $72^{\circ} \mathrm{C}$ extension $(1 \mathrm{~min})$; a final extension at $72^{\circ} \mathrm{C}$ for $10 \mathrm{~min}$.

The PCR amplification was carried out in a GeneAmp ${ }^{\circledR}$ PCR System 9700 (PE Applied Biosystems Inc.) with a 20 $\mu \mathrm{L}$ reaction mixture containing $2 \mu \mathrm{L} 10 \times$ PCR buffer (including $2.5 \mathrm{mM} \mathrm{MgCl}_{2}$ ), $2 \mu \mathrm{L}$ dNTP Mix (2.5 mM each), $1 \mu \mathrm{L} 10 \mu \mathrm{M}$ each primer, 2-5 $\mu$ g template DNA, 0.5 $\mu \mathrm{L}$ dimethyl sulfoxide (DMSO) and $1.5 \mathrm{U}$ Taq DNA polymerase. All PCR products were separated by $1.5 \%$ $(\mathrm{w} / \mathrm{v})$ agarose TAE gel, and purified using TIANgel midi purification Kit (Tiangen Biotech (Beijing) Co. Ltd.). Then the PCR products were ligated with the pMD 18-T vector (Takara Biotechnology (Dalian) Co. Ltd.). Competent JM109 cells were transformed into the ligation products, and the correct colonies were identified by LB solid medium (IPTG, X-gal, Amp +) and bacteria PCR. The sequencing products were analyzed by Invitrogen Biotechnology (Shanghai) Co. Ltd. All products were 
Table 2. Sequences characteristics of ITS sequence in this study.

\begin{tabular}{|l|c|c|c|}
\hline \multicolumn{1}{|c|}{ Sequences characteristics } & ITS1 & $\mathbf{5 . 8 S}$ & ITS2 \\
\hline Length range (bp) & $215-216$ & 162 & $221-223$ \\
\hline Constant sites No. (\%) & $150(69.12)$ & $153(94.44)$ & $153(68.30)$ \\
\hline Parsimony-informative sites No. (\%) & $38(17.51)$ & $5(3.09)$ & $34(15.18)$ \\
\hline Autapomorphic sites No. (\%) & $29(13.36)$ & $4(2.47)$ & $37(16.52)$ \\
\hline G + C content range (\%) & $52.31-57.87$ & $53.70-54.94$ & $53.39-57.92$ \\
\hline G + C content mean (\%) & 55.00 & 54.71 & 55.58 \\
\hline Sequence divergence range (\%) & $0.46-17.97$ & $0.00-2.47$ & $0.00-16.96$ \\
\hline
\end{tabular}

sequenced by forward and reverse reactions for sequence confirmation. The sequencing chromatograms were assembled using SeqMan of DNAStar software package, and the sequences were aligned using the ClustalW in MegAlign. For ITS sequences, the sequence boundaries of ITS1, 5.8S and ITS2 were defined based on the conserved sequences of Dacus carota (Yokota et al. 1989). For the sequences amplified by the specific primers, the Clustal X, version 1.8 (Thompson et al. 1997) was used for alignment with the complete sequences of Angelica species to verify the sources of adulterants.

\section{Primer design}

Based on the ITS sequence data, a pair of specific primers, PF and PR, was designed. The forward primer was: 5'GAATGACCCGCTAACACGTT-3', and the reverse primer was: 5'-CGACAAGACAAGAGGGTC-3' (Figure 1). The PCR reaction mixture $(20 \mu \mathrm{L})$ contained $2 \mu \mathrm{L} 10 \mathrm{x}$ PCR buffer (including $2.5 \mathrm{mM} \mathrm{MgCl}$ ), $2 \mu \mathrm{L}$ dNTP Mix (2.5 mM each), $1 \mu \mathrm{L} 10 \mu \mathrm{M}$ each primer, $2-5 \mu$ g template DNA, $0.5 \mu \mathrm{L}$ DMSO and 1.5-2 U Taq DNA polymerase. And the PCR amplification was carried out under the following conditions: initial denaturation at $94^{\circ} \mathrm{C}(3 \mathrm{~min})$; followed by 30 cycles of $94^{\circ} \mathrm{C}$ denaturation $(1 \mathrm{~min}), 65^{\circ} \mathrm{C}$ annealing $(1 \mathrm{~min})$, and $72^{\circ} \mathrm{C}$ extension $(1 \mathrm{~min})$; a final extension for $10 \mathrm{~min}$ at $72^{\circ} \mathrm{C}$.

The specific primers, $\mathrm{PF}$ and $\mathrm{PR}$, were used to amplify the genomic DNA of $A$. sinensis and seven regional substitutes, A. nitida, A. valida, A. megaphylla, A. apaensis, A. laxifoliata, A. fargesii, A. pseudoselinum. And we tested eight commercially crude materials purchased in the market by the specific primers, PF and PR. The separation and sequencing of PCR products were performed under the experimental conditions mentioned above.

\section{Phylogenetic analysis}

Maximum parsimony (MP) analysis was performed using PAUP* ver. 4.0b10 (Swofford, 2003). For the heuristic search, all character transformations were weighted equally and gaps were treated as missing data. The heuristic search was performed using the following options: tree bisectionreconnection (TBR) branch swapping, addseq in 100 random-addition replicates, multrees and steepest in effect. Bootstrap resampling was performed using the same options with 1000 replications. Cicuta virosa was set as outgroup according to the systematic relationships of Chinese Apiaceae subfamily Apioideae (Zhou et al. 2008). The ITS sequences were checked for the conserved motifs of ITS1 region (Liu and Schardl, 1994). The taxa and GenBank accession numbers of ITS sequences used by phylogenetic analysis in this paper are listed in Appendix.

\section{RESULTS}

A motif of ITS1 sequences ("GGCRY-(4 to 7 n)GYGYCAAGGAA”) was confirmed previously (Liu and Schardl, 1994). In this study, a similar highly conserved region "GGCGC-GGnAn-GCGCCAAGGA" (136-155 bp) was also recognized. On average, ITS1 was slightly shorter than ITS2, but it provided parsimony informative sites almost as much as ITS2. The means of guanine-cytosine (GC) content were approximate in ITS1 and ITS2 sequences (Table 2).

Alignment of 20 complete ITS sequences resulted in a matrix of 607 characters. Parsimony analysis of all sequences resulted in 271 most-parsimonious trees. Including and excluding uniformative characters, the consistency indices (CI) of strict consensus tree were 0.793 and 0.676 , and homoplasy indices (HI) were 0.207 and 0.324 , respectively. The retention index (RI) was 0.736 , and the rescaled consistency index (RC) was 0.584 . 


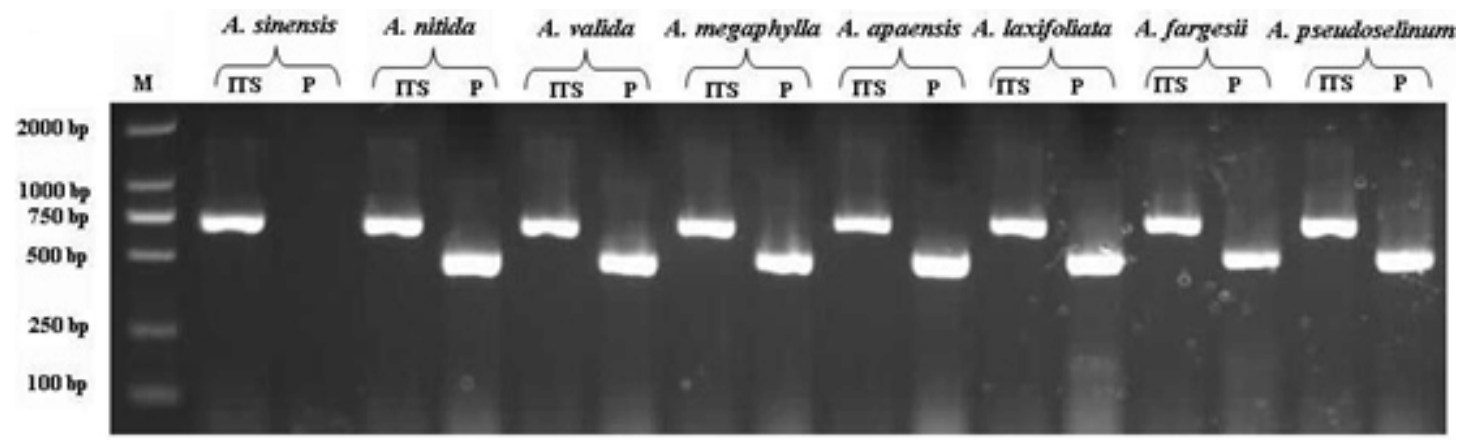

Figure 3. PCR amplication of nrDNA ITS regions from different Angelica species. ITS: samples amplified using ITS4 and ITS5 primers showing the presence of $A$. sinensis. P: samples amplified using specific primers showing the presence of adulterants. M: DNA marker.

In the MP tree, the Angelica species resulted in two distinctly major clades (clade A and B) (Figure 2). Clade A included most of Angelica species and received high bootstrap values (100\%). In clade A, the familiar adulterants and regional substitutes composed group C, which was supported by high bootstrap values (95\%). Clade B encompassed only two Angelica species, A. sinensis and $A$. tianmuensis. The high bootstrap values (93\%) of clade $B$ indicated that the phylogenetic relationship between $A$. sinensis and $A$. tianmuensis was affinitive. However, as an endemic species, A. tianmuensis was not the regional substitute because of it's limited distributing region.

The universal primers (ITS4 and ITS5) successfully amplified the single DNA band for all Angelica species, including seven regional substitutes and $A$. sinensis. The fragment of products amplified by the universal primers were approximately $700 \mathrm{bp}$ (Figure 3 ).

The specific primers (PF and PR) were designed based on the divergent ITS regions. The specific forward primer PF matched on the position of 19 to $38 \mathrm{bp}$ in ITS1 region, while the reverse primer PR located at position 523 to 540 bp in ITS2 region (Figure 1). The fragments of products amplified by specific primers (PF and PR) from all seven regional substitutes were 516 bp (Table 3). The primers, PF and PR, amplified the specific products from the seven regional substitutes, but did not amplify specific product from the $A$. sinensis (Figure 3 ). The results proved that the specific primers are efficient in authenticating genuine crude materials from adulterants and regional substitutes.

We used the universal primers (ITS4 and ITS5) and specific primers ( $\mathrm{PF}$ and $\mathrm{PR}$ ) to test eight commercially crude materials which were purchased in the market (Figure 4). All these eight samples were successfully amplified by the universal primers, with the result of same electrophoresis patterns. Specific PCR products were amplified from four samples (sample A, B, C and D) by the specific primers. This indicated that these four samples contained the adulterants though they were named "Dang gui" in the market. We subcloned and sequenced the specific PCR products, the results showed that samples A and $\mathrm{B}$ were both adulterated with $A$. laxifoliata and $A$. nitida, while samples $\mathrm{C}$ and $\mathrm{D}$ were adulterated with $A$. laxifoliata (Table 3). No specific products were amplified from four other samples (sample E, F, G and $\mathrm{H}$ ) by the specific primers. This result indicated that there were genuine crude materials (A. sinensis) in these four samples.

\section{DISCUSSION}

The GC balance between ITS1 and ITS2 is a common

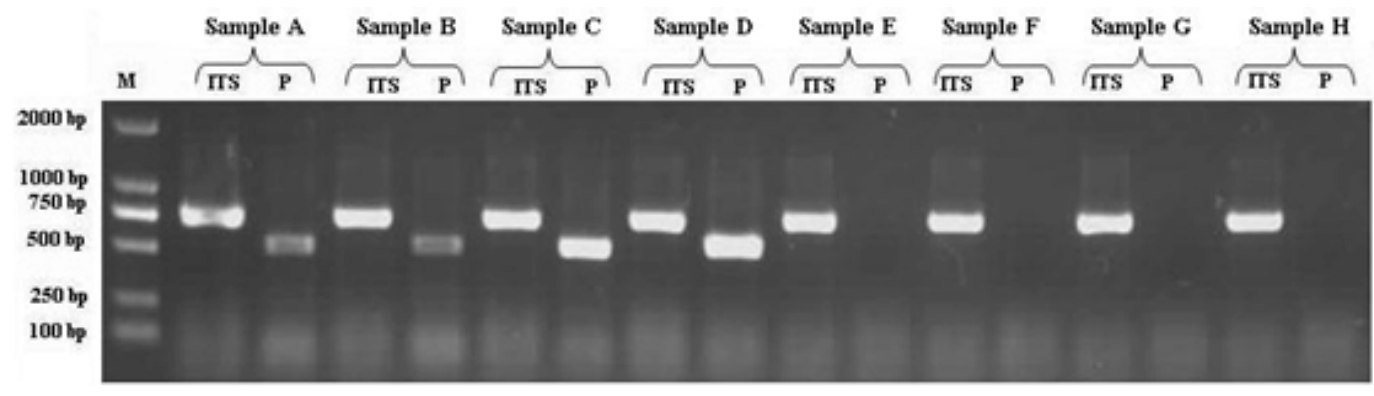

Figure 4. Testing PCR amplication of eight commercially crude materials. ITS: samples amplified using ITS4 and ITS5 primers showing the presence of $A$. sinensis. P: samples amplified using specific primers showing the presence of adulterants. M: DNA marker. 
feature and obviously presented in all eukaryotic taxa, which phenomenon called molecular coevolution and might linked to the functional structures. The ITS1 and ITS2 sequences appeared to function in the maturation of nuclear ribosomal RNAs, i.e., the ITS1 has probably been a spacer, and the ITS2 was considered to be a former expansion segment (Liang and Fournier, 1997). The balanced G + C content and conserved motif of ITS indicated the significant functional role of ITS for the rRNA primary transcript processing (Torres et al. 1990).

In the phylogenetic tree, the seven familiar adulterants and regional substitutes encompassed group $\mathrm{C}$ and segregated from $A$. sinensis. The phylogenetic result also showed that there were great genetic variations within the Angelica species derived from the ITS sequences, and it was feasible to design a pair of specific primers based on the divergent ITS region to authenticate the genuine materials from adulterants and regional substitutes.

With increasing demands for edible and medicinal herb $A$. sinensis, the adulterants and regional substitutes inevitably appeared in the market and some areas. Therefore, authentication of those species shows great secure significance for consumers.

Traditionally, the authenticating methods for the A. sinensis and adulterants are mainly based on the morphological characters observed from their original plants: leaf sheaths smooth or spinulose, number of bracts, shape of bracteole, number of vittae at vallecula and commissure, basal and lower cauline leaves ternate or pinnate; and the characters of their root: the shape and texture of roots, colour of root and cutting surgace, presence or absence of ray fiber, etc. The analysis of compounds relies on the amounts of samples and the stability of compounds. Withal, the phenotypic characters and compounds inevitably change in different habitat and processes. In general, the authentication based on morphological characters and analysis of compounds are subtle and ambiguous (Yang et al. 2007). Several molecular methods, e.g. PCR-RFLP,
ARMS, AP-PCR, RAPD, SCAR, have recently been used for the authentication of medicinal plants. Although they have been proven to be efficient in taxonomic identification and distinguishing genuine crude drugs from their substitutes or adulterants, the applications of these methods are limited by different conditions of experiments. For RAPD, the reproducibility is heavily affected by the quality and concentration of template DNA, the ratio of template DNA to primers, and slight fluctuations of reacting components or cycling parameters. In regards to the PCRRFLP method, the length of PCR products also confined its utilization, as the number of restriction enzyme sites is limited in sequence segments between two primers (Wang et al. 2000; Shaw et al. 2002; Lian et al. 2008). As diagnostic tools, the ITS sequences are especially useful for authenticating substitutes or adulterants which contain morphologically and/or phytochemically indistinguishable species (Joshi et al. 2004).

This study presented an efficient method for authenticating TCM on species level. Based on the ITS sequence analysis of $A$. sinensis and seven regional substitutes, we designed a pair of specific primers which exactly match the specific DNA sequence of adulterants but incompletely match with the sequence of $A$. sinensis. Therefore, a highly sensitive PCR reaction with specific primers for adulterants gave positive signal, but not for genuine species, A. sinensis. Furthermore, the process of authentication by PCR is very simple and convenient to use.

The molecular authentication results from eight commercially crude materials indicated that there were adulterants for $A$. sinensis in the market. For the four adulterate samples (sample A, B, C, and D), the adulterants are A. laxifoliata and A. nitida. These two Angelica species are widely distributed in Southwest China, and it is difficult to be distinguished from $A$. sinensis because of their morphological resemblances. The complexity of adulteration may be caused by the misidentification of species in the process of herborization and breeding. The confusion of the genuine resources compromises the

Table 3. The sequences amplified by specific primers of commercially crude materials.

\begin{tabular}{|c|c|c|c|}
\hline Sample code & Adulterants & Length (bp) & Accession number \\
\hline A & A. laxifoliata & 516 & FJ228464 \\
\hline A & A. nitida & 516 & FJ228465 \\
\hline B & A. laxifoliata & 516 & FJ228466 \\
\hline B & A. nitida & 516 & FJ228467 \\
\hline C & A. laxifoliata & 516 & FJ228468 \\
\hline D & A. laxifoliata & 516 & FJ228469 \\
\hline
\end{tabular}


therapeutic value of $A$. sinensis and endangers the safety of the consumers. In this study, the specific primers, PF and $\mathrm{PR}$, were efficient in authenticating genuine crude materials from adulterants and regional substitutes.

Besides the ITS sequences, there are a great deal of genes and non-coding regions in genomic DNA, such as trnK, trnL-trnF, Chalcone Synthase (CHS), which have the priority of authentication and identification at interspecificlevel and intergeneric-level of plants. Therefore, we can explore more molecular markers of genomic DNA as diagnostic tools for authentication purpose. Several sequences in chloroplast are used in authenticating for traditional Chinese medicines, such as Actinidia macrosperma, medicinal rhubarb (Yang et al. 2001; Zhao et al. 2007). Compared with the molecular markers in chloroplast, the nrDNA ITS sequences widely exist in plant tissues like leaves, roots, even seeds. Therefore, ITS sequences show more widely prospect in authenticating medicinal plants.

In conclusion, molecular authentication of $A$. sinensis based on ITS sequence is a highly sensitive and stable method. The authentication results are reliable and not affected by the physical form or physiological conditions of the plant samples. Therefore, the method derived from nrDNA ITS sequence in this study could be used for practical and accurate authentication of $A$. sinensis and adulterants, and might be contributed to raw material production and quality control of $A$. sinensis.

\section{ACKNOWLEDGMENTS}

The authors wish to thank Ms. Hai-yan Liu, Dr. Yun-dong Gao, Dr. Yan Yu for collecting the samples in fields. The authors greatly appreciate Dr. Kun Wei for improving of the manuscript and the anonymous reviewer for helpful criticism.

\section{REFERENCES}

ÁLVAREZ, I. and WENDEL, J.F. Ribosomal ITS sequences and plant phylogenetic inference. Molecular Phylogenetics and Evolution, December 2003, vol. 29, no. 3, p. 417-434.

BALDWIN, B.G.; SANDERSON, M.J.; PORTER, J.M.; WOJCIECHOWSKI, M.F.; CAMPBELL, C.S. and DONOGHUE, M.J. The ITS region of nuclear ribosomal DNA: a valuable source of evidence on angiosperm phylogeny. Annals of the Missouri Botanical Garden, 1995, vol. 82, no. 2, p. 247-277.

BIFFIN, E.; HARRINGTON, M.G.; CRISP, M.D.; CRAVEN, L.A. and GADEK, P.A. Structural partitioning, paired-sites models and evolution of the ITS transcript in Syzygium and Myrtaceae. Molecular Phylogenetics and Evolution, April 2007, vol. 43, no. 1, p. 124-139.

COTA-SÁNCHEZ, J. Hugo; REMARCHUK, Kirsten and UBAYASENA, Kumary. Ready-to-use DNA extracted with a CTAB method adapted for herbarium specimens and mucilaginous plant tissue. Plant Molecular Biology Reporter, June 2006, vol. 24, no. 2, p. 161-167.

DING, Xiaoyu; WANG, Zhengtao; ZHOU, Kaiya; XU, Luoshan; XU, Hong and WANG, Yiquan. Allele-specific primers for diagnostic PCR authentication of Dendrobium officinale. Planta Medica, June 2003, vol. 69, no. 6, p. 587588.

DOWNIE, Stephen R.; KATZ-DOWNIE, Deborah S. and WATSON, Mark F. A phylogeny of the flowering plant family Apiaceae based on chloroplast DNA rpl16 and rpoc1 intron sequences: towards a suprageneric classification of subfamily Apioideae. American Journal of Botany, February 2000, vol. 87, no. 2, p. 273-292.

Editorial Board of Pharmacopoeia of the People's Republic of China. Pharmacopoeia of the People's Republic of China (in Chinese). Bei Jing, Chemical Industry Press, 2005. vol. 1, 89. p. ISBN 7502565248.

GUO, Yahong; KONDO, Kenji; TERABAYASHI, Susumu; YAMAMOTO, Yutaka; SHIMADA, Hiroshi; FUJITA, Masao; KAWASAKI, Takeshi; MARUYAMA, Takuro; GODA, Yukihiro and MIZUKAMI, Hajime. DNA authentication of So-jutsu (Atractylodes lancea rhizome) and Byaku-jutsu (Atractylodes rhizome) obtained in the market based on the nucleotide sequence of the 18S-5.8S rDNA internal transcribed spacer region. Journal of Natural Medicines, April 2006, vol. 60, no. 2, p. 149-156.

JOSHI, Kalpana; CHAVAN, Preti; WARUDE, Dnyaneshwar and PATWARDHAN, Bhushan. Molecular markers in herbal drug technology. Current Science, July 2004, vol. 87, no. 2, p. 159-165.

KIM, Ok Tae; BANG, Kyong Hwan; IN, Dong Su; LEE, Jei Wan; KIM, Young Chang; SHIN, Yoo Soo; HYUN, Dong Yun; LEE, Sung Sik; CHA, Seon Woo and SEONG, Nak Sul. Molecular authentication of ginseng cultivars by comparison of internal transcribed spacer and 5.8S rDNA sequences. Plant Biotechnology Reports, August 2007, vol. 1, no. 3, p. 163-167.

LAU, David Tai-Wai; SHAW, Pang-Chui; WANG, Jun and BUT, Paul Pui-Hay. Authentication of medicinal Dendrobium species by the internal transcribed spacer of ribosomal DNA. Planta Medica, 2001, vol. 67, no. 5, p. 456-460.

LEE, Chang-Shook and DOWNIE, Stephen R. Phylogenetic relationships within Cicuta (Apiaceae tribe Oenantheae) inferred from nuclear rDNA ITS and cpDNA sequence data. Canadian Journal of Botany, March 2006, vol. 84, no. 3, p. 453-468.

LIAN, Bin; ZANG, Jin-ping; HOU, Wei-guo; YUAN, Sheng and SMITH, Donald L. PCR-based sensitive 
detection of the edible fungus Boletus edulis from rDNA ITS sequences. Electronic Journal of Biotechnology, January 2008, vol. 11, no. 3.

LIANG, Wen-Qing and FOURNIER, Maurille J. Synthesis of functional eukaryotic ribosomal RNAs in trans: Development of a novel in vivo rDNA system for dissecting ribosome biogenesis. Proceedings of the National Academy of Sciences of the United States of America, April 1997, vol. 94, no. 7, p. 2864-2868.

LIN, Juan; ZHOU, Xuanwei; GAO, Shi; WU, Weisheng; LIU, Xiaojun; SUN, Xiaofen and TANG, Kexuan. Authentication of Pinellia ternata and its adulterants based on PCR with specific primers. Planta Medica, July 2006, vol. 72, no. 9, p. 844-847.

LIU, Jih-Shiou and SCHARDL, Christopher L. A conserved sequence in internal transcribed spacer 1 of plant nuclear rRNA genes. Plant Molecular Biology, October 1994, vol. 26, no. 2, p. 775-778.

LU, Guang-Hua; CHAN, Kelvin; LIANG, Yi-Zeng; LEUNG, Kelvin; CHAN, Chi-Leung; JIANG, Zhi-Hong and ZHAO, Zhong-Zhen. Development of highperformance liquid chromatographic fingerprints for distinguishing Chinese Angelica from related umbelliferae herbs. Journal of Chromatography A, May 2005, vol. 1073, no. 1-2, p. 383-392.

NGAN, F.; SHAW, P.; BUT, P. and WANG, J. Molecular authentication of Panax species. Phytochemistry, March 1999, vol. 50, no. 5, p. 787-791.

SHAW, P.C.; WANG, J. and BUT, P.P.H. Authentication of Chinese medicinal materials by DNA technology. Hackensack; World Scientific Publishing, 2002. 244 p. ISBN 9789810246211.

SHE, M.L.; PU, F.T.; PAN, Z.H.; WATSON, M.F.; CANNON, J.F.M.; HOLMES-SMITH, I.; KLJUYKOV, E.V.; PHILLIPPE, L.R. and PIMENOV, M.G. Apiaceae. In: Flora of China Editorial Committee. ed. Flora of China. St. Louis, Missouri; Missouri Botanical Garden Press, 2005, vol. 14, p. 1-205.

SWOFFORD, D.L. PAUP*: Phylogenetic analysis using parsimony (*and other methods). [CD-ROM]. Version 4.0 b10. Sunderland, MA, Sinauer Associates, c. 2003.

THOMPSON, J.D.; GIBSON, T.J.; PLEWNIAK, F.; JEANMOUGIN, F. and HIGGINS, D.G. The CLUSTAL_X windows interference: Flexible strategies for multiple sequence alignment aided by quality analysis tools. Nucleic Acids Research, December 1997, vol. 25, no. 24, p. 4876-4882.

TORRES, Ramon A.; GANAL, Martin and HEMLEVEN, Vera. GC balance in the internal transcribed spacers ITS1 and ITS2 of nuclear ribosomal RNA genes. Journal of
Molecular Evolution, February 1990, vol. 30, no. 2, p. 170181.

WANG, Shuai; MA, Hua-Qiao; SUN, Ya-Jie; QIAO, Cheng-Dong; SHAO, Shi-Jun and JIANG, Sheng-Xiang. Fingerprint quality control of Angelica sinensis (Oliv.) Diels by high-performance liquid chromatography coupled with discriminant analysis. Talanta, April 2007, vol. 72, no. 2, p. 434-436.

WANG, Yiquan; ZHOU, Kaiya; XU, Luoshan; DONG, Tina T.X. and TSIM, Karl W.K. Authentication of an animal crude drug, Zaocys, by diagnostic PCR. Biological and Pharmaceutical Bulletin, May 2000, vol. 23, no. 5, p. 585-588.

WHITE, T.J.; BRUNS, T.D.; LEE, S.B. and TAYLOR, J.W. Amplification and direct sequencing of fungal ribosomal RNA Genes for phylogenetics. In: INNS, M.A.; GELFAND, D.H.; SNINSKY, J.J. and WHITE, T.J. eds. PCR Protocols: A Guide to Methods and Applications. San Diego, California; Academic Press, 1990, p. 315-322.

XU, Hong; WANG, Zhengtao; DING, Xiaoyu; ZHOU, Kaiya and XU, Luoshan. Differentiation of Dendrobium species used as "Huangcao Shihu" by rDNA ITS sequence analysis. Planta Medica, November 2006, vol. 72, no. 1, p. 89-92.

XUE, Heng-Gang; ZHOU, Song-Dong; HE, Xing-Jin and YU, Yan. Molecular authentication of the traditional chinese medicinal plant Euphorbia pekinensis. Planta Medica, January 2006, vol. 73, no. 1, p. 91-93.

XUE, Hua-Jie; YAN, Mao-Hua; LU, Chang-Mei; WANG, Nian-He and WU, Guo-Rong. Taxonomic study of Angelica from East Asia: inferences from ITS sequences of nuclear ribosomal DNA. Acta Phytotaxonomica Sinica, November 2007, vol. 45, no. 6, p. 783-795.

YANG, Meihua; ZHANG, Daming; LIU, Jianquan and ZHENG, Junhua. A molecular marker that is specific to medicinal rhubarb based on chloroplast $\operatorname{trnL} / \operatorname{trn} F$ sequences. Planta Medica, November 2001, vol. 67, no. 8, p. 784-786.

YANG, Qing; POPULO, Stephen M.; ZHANG, Jianying Y.; YANG, Guoguang and KODAMA, Hiroyuki. Effect of Angelica sinensis on the proliferation of human bone cells. Clinica Chimica Acta, October 2002, vol. 324, no. 1-2, p. 89-97.

YANG, Zhi-Ye; CHAO, Zhi; HUO, Ke-Ke; XIE, Hui; TIAN, Zhi-Peng and PAN, Sheng-Li. ITS sequence analysis used for molecular identification of the Bupleurum species from northwestern China. Phytomedicine, June 2007, vol. 14, no. 6, p. 416-423.

YE, Y.N.; KOO, M.W.L.; LI, Y.; MATSUI, H. and CHO, C.H. Angelica sinensis modulates migration and 
proliferation of gastric epithelial cells. Life Sciences, January 2001, vol. 68, no. 8, p. 961-968.

YE, Y.N.; SO, H.L.; LIU, E.S.L.; SHIN, V.Y. and CHO, C.H. Effect of polysaccharides from Angelica sinensis on gastric ulcer healing. Life Sciences, January 2003, vol. 72, no. 8, p. 925-932.

YOKOTA, Yukihiko; KAWATA, Takefumi; IIDA, Yoichi; KATO, Atsushi and TANIFUJI, Shigeyuki. Nucleotide sequence of the 5.8S rRNA gene and internal transcribed spacer regions in carrot and broad bean ribosomal DNA. Journal of Molecular Evolution, October 1989, vol. 29, no. 4, p. 294-301.

ZHAO, Yun-Peng; QIU, Ying-Xiong; GONG, Wei; LI, Jian-Hua and FU, Cheng-Xin. Authentication of Actinidia macrosperma using PCR-RFLP based on trnK sequences. Botanical Studies, 2007, vol. 48, no. 3, p. 239-242.

ZHOU, Jing; PENG, Hua; DOWNIE, Stephen R.; LIU, Zhen-Wen and GONG, Xun. A molecular phylogeny of Chinese apiaceae subfamily apioideae inferred from nuclear ribosomal DNA internal transcribed spacer sequences. Taxon, May 2008, vol. 57, no. 2, p. 402-416. 
Feng, T. et al.

Appendix. Taxa and GenBank accession numbers of sequences in this paper.

\begin{tabular}{|c|c|c|}
\hline Taxa & GenBank accession numbers & Reference \\
\hline $\begin{array}{l}\text { A. acutiloba } \\
\text { (Siebold and Zuccarini) Kitagawa }\end{array}$ & DQ278165 & Xue et al. 2007 \\
\hline $\begin{array}{l}\text { A. amurensis } \\
\text { Schischkin in Schischkin and Bobrov }\end{array}$ & DQ263581 & Xue et al. 2007 \\
\hline $\begin{array}{l}\text { A. apaensis } \\
\text { R. H. Shan and C. Q. Yuan }\end{array}$ & EU418381 & this study \\
\hline $\begin{array}{l}\text { A. biserrata } \\
\text { C. Q. Yuan and R. H. Shan }\end{array}$ & DQ270207 & Xue et al. 2007 \\
\hline $\begin{array}{l}\text { A. cartilaginomarginata var. foliosa } \\
\text { C. Q. Yuan and R. H. Shan }\end{array}$ & DQ263589 & Xue et al. 2007 \\
\hline $\begin{array}{l}\text { A. fargesii } \\
\text { H. de Boissieu }\end{array}$ & EU418376 & this study \\
\hline $\begin{array}{l}\text { A. genuflexa } \\
\text { Nuttall. }\end{array}$ & DQ263566 & Xue et al. 2007 \\
\hline $\begin{array}{l}\text { A. gigas } \\
\text { Nakai }\end{array}$ & DQ263580 & Xue et al. 2007 \\
\hline $\begin{array}{l}\text { A. laxifoliata } \\
\text { Diels }\end{array}$ & EU647210 & this study \\
\hline $\begin{array}{l}\text { A. megaphylla } \\
\text { Diels }\end{array}$ & EU418377 & this study \\
\hline $\begin{array}{l}\text { A. morii } \\
\text { Hayata }\end{array}$ & DQ263578 & Xue et al. 2007 \\
\hline $\begin{array}{l}\text { A. nitida } \\
\text { Wolff }\end{array}$ & EU418378 & this study \\
\hline $\begin{array}{l}\text { A. omeiensis } \\
\text { Yuan and Shan }\end{array}$ & DQ263576 & Xue et al. 2007 \\
\hline $\begin{array}{l}\text { A. polymorpha } \\
\text { Maxim }\end{array}$ & DQ263590 & Xue et al. 2007 \\
\hline $\begin{array}{l}\text { A. pseudoselinum } \\
\text { H. de Boissieu }\end{array}$ & EU418379 & this study \\
\hline $\begin{array}{l}\text { A. sinensis } \\
\text { (Oliver) Diels }\end{array}$ & FJ204235 & this study \\
\hline $\begin{array}{l}\text { A. tsinlingensis } \\
\text { K.T. Fu }\end{array}$ & DQ263577 & GenBank \\
\hline $\begin{array}{l}\text { A. tianmuensis } \\
\text { Z.H. Pan, and T.D. Zhuang }\end{array}$ & DQ270194 & Xue et al. 2007 \\
\hline $\begin{array}{l}\text { A. valida } \\
\text { Diels }\end{array}$ & EU418380 & this study \\
\hline Cicuta virosa Linn. & AY524767 & Lee and Downie, 2006 \\
\hline
\end{tabular}

